\title{
A General Circulation Model Study of Atmospheric Carbon Monoxide
}

\author{
Joseph P. Pinto, Yuk L. Yung, ${ }^{1}$ David Rind, Gary L. Russell, Jean A. Lerner, James E. Hansen, and \\ SUlTAN HAMEED ${ }^{2}$
}

NASA Goddard Space Flight Center, Institute for Space Studies, New York, New York 10025

\begin{abstract}
The carbon monoxide cycle is studied by incorporating the known and hypothetical sources and sinks in a tracer model that uses the winds generated by a general circulation model. Photochemical production and loss terms, which depend on $\mathrm{OH}$ radical concentrations, are calculated in an interactive fashion. The computed global distribution and seasonal variations of $\mathrm{CO}$ are compared with observations to obtain constraints on the distribution and magnitude of the sources and sinks of $\mathrm{CO}$, and on the tropospheric abundance of $\mathrm{OH}$. The simplest model that accounts for available observations requires a low latitude plant source of about $1.3 \times 10^{15} \mathrm{~g} \mathrm{yr}^{-1}$, in addition to sources from incomplete combustion of fossil fuels and oxidation of methane. The globally averaged $\mathrm{OH}$ concentration calculated in the model is $7 \times 10^{5}$ $\mathrm{cm}^{-3}$. Models that calculate globally averaged $\mathrm{OH}$ concentrations much lower than our nominal value are not consistent with the observed variability of $\mathrm{CO}$. Such models are also inconsistent with measurements of $\mathrm{CO}$ isotopic abundances, which imply the existence of plant sources.
\end{abstract}

\section{INTRODUCTION}

Carbon monoxide is the third most abundant carbon species in the atmosphere (after carbon dioxide and methane), but its roles in the atmospheric and biogeochemical cycles of carbon are not quantitatively understood. An understanding of the $\mathrm{CO}$ cycle is important in its own right, for the information it implies with regard to the global dispersal of atmospheric pollutants, and for an assessment of perturbations of tropospheric chemistry by man's activities. Early work on carbon monoxide included its discovery in the infrared solar absorption spectrum by Migeotte [1949] and an investigation of its potential sources and sinks by Bates and Witherspoon [1952]. The subject remained dormant for nearly 2 decades until the importance of the hydroxyl radical in tropospheric chemistry was recognized [Levy, 1971; McConnell et al., 1971]. The hydroxyl radical is derived from

$$
\begin{gathered}
\mathrm{O}_{3}+h v \rightarrow \mathrm{O}_{2}+\mathrm{O}\left({ }^{1} D\right) \\
\mathrm{O}\left({ }^{1} D\right)+\mathrm{H}_{2} \mathrm{O} \rightarrow 2 \mathrm{OH}
\end{gathered}
$$

The reaction

$$
\mathrm{CO}+\mathrm{OH} \rightarrow \mathrm{CO}_{2}+\mathrm{H}
$$

provides the only important sink for $\mathrm{CO}$ in the gas phase and is responsible for determining the chemical lifetime of $\mathrm{CO}$ in the atmosphere. In addition to destroying $\mathrm{CO}$, the hydroxyl radical also destroys $\mathrm{CH}_{4}$

$$
\mathrm{CH}_{4}+\mathrm{OH} \rightarrow \mathrm{H}_{2} \mathrm{O}+\mathrm{CH}_{3}
$$

Reaction (R16) initiates a sequence of reactions that ultimately leads to the production of $\mathrm{CO}$. As was first pointed out by McConnell et al. [1971], (R16) represents a major source of CO, especially in the clean troposphere. It was argued [see Wofsy, 1976] that this source, together with that derived from incomplete combustion of fossil fuels [Bates and Witherspoon, 1952], could account for the budget of atmospheric CO. However, later experiments [see, for example, Biermann et al., 1978] showed that reaction (R18), which is primarily responsible for

\footnotetext{
${ }^{1}$ California Institute of Technology, Pasadena, California 91125.

2 State University of New York, Stony Brook, New York 11794.

Copyright 1983 by the American Geophysical Union.

Paper number 3C0077.
}

0148-0227/83/003C-0077\$05.00 removing $\mathrm{CO}$, is pressure-dependent in the presence of oxygen and should proceed nearly twice as fast as previously thought. A renewed search for sources of $\mathrm{CO}$ suggested that oxidation of nonmethane hydrocarbons (NMHC), especially isoprenes and terpenes emitted by trees [Zimmerman et al., 1978] and biomass burning [Crutzen et al., 1979] could be important. However, it is difficult to quantify the magnitudes of these sources (see Logan et al. [1981] for a detailed catalog and assessment of the uncertainties).

The intense interest in $\mathrm{CO}$ in the last decade resulted in the generation of an extensive data base concerning its spatial distribution [see, for example, Seiler, 1974] and seasonal variation [Seiler et al., 1976; Dianov-Klokov et al., 1978]. Previous theoretical studies of the $\mathrm{CO}$ cycle include photochemical models that neglected horizontal transport [Wofsy,1976; Crutzen and Fishman, 1977; Logan et al., 1981] and Hameed and Stewart's [1979] model, which considered north-south mixing by diffusion. However, the chemical lifetime of $\mathrm{CO}$ is believed to be at least several weeks, and, hence, both chemistry and transport should play a role in determining the $\mathrm{CO}$ concentration as a function of height, latitude, and season. A study of the $\mathrm{CO}$ cycle with a three-dimensional global model, which explicitly accounts for atmospheric motions, should therefore be useful for helping to identify and quantify the sources and sinks of $\mathrm{CO}$ in a self consistent manner. Greater weight should also be given to tropospheric $\mathrm{OH}$ calculations that are consistent with the major features of the global $\mathrm{CO}$ cycle. Because $\mathrm{OH}$ determines the $\mathrm{CO}$ lifetime, and the strength of the methane oxidation source, and reaction with $\mathrm{CO}$ is the major loss for $\mathrm{OH}$, we must calculate $\mathrm{OH}$ concentrations in an interactive manner. The nature of this coupling between $\mathrm{CO}$ and $\mathrm{OH}$ is such that additional $\mathrm{CO}$-sourees require higher- $\Theta H$ eoncentrations and vice versa. We will use three independent pieces of information in the $\mathrm{CO}$ data base to constrain our predicted OH concentrations; these are (1) the latitudinal variation of $\mathrm{CO},(2)$ its vertical variation, especially in the tropics, and (3) its seasonal variation. Since we can estimate the magnitude of anthropogenic emissions to better than a factor of 2 , there is essentially one remaining free parameter in our model, the magnitude of plant sources in the tropics. A large number of other parameters have also been tested, but they were shown to be unimportant. Since we have used measurements of $\mathrm{CO}$ variability as a measure of its chemical lifetime, we regard our derived $\mathrm{OH}$ concentrations as empirical values that satisfy 
these observations. Their validity should therefore transcend the assumptions of our simplified chemical model.

In the following section we briefly describe the threedimensional transport model used in our studies. In the subsequent section we describe several experiments used to investigate the $\mathrm{CO}$ cycle. In the final two sections we discuss the results and implications of the experiments.

\section{DESCRIPTION OF THE MODEL}

The numerical experiments were performed with the general circulation model described by Hansen et al. [1983]. The general circulation model is global in extent, with a horizontal resolution of $8^{\circ} \times 10^{\circ}$ (latitude $\times$ longitude). Seven layers, evenly spaced in $\sigma$ coordinates, were employed between the surface and $10 \mathrm{mbar}(31 \mathrm{~km})$, with at least one layer entirely within the stratosphere at all locations. The model was run for 5 years, and the necessary dynamical variables for the fifth year stored off line for use in a 'tracer model.' Compared with climatological data, the three-dimensional wind fields, temperatures, and humidity, have a rough correspondance with reality. An indication of the representativeness of the model's wind fields is presented in Figure $1 a$ for the surface winds in February and in Figure $1 b$ for the jet stream winds at 315 mbar level. The surface wind pattern shows the expected latitudinal variation, with easterlies at low latitudes and cyclonic and anticyclonic circulations at high latitudes. The southeast and northeast trade winds converge near the equator, the pattern being more apparent over the ocean, where frictional effects are less than that over land. Anticyclonic patterns dominate over the oceans near $30^{\circ}$ latitude, typical of the subtropical high pressure system. At about $50^{\circ} \mathrm{N}$ latitude, the Aleutian low in the midPacific and the Icelandic low in the North Atlantic produce cyclonic wind patterns, while prevailing westerlies occur over the United States and Asia. In the southern hemisphere, strong west winds are evident near $60^{\circ} \mathrm{S}$. All these features predicted by our model also exist in observations. At the jet stream level, strong winds are evident from $30^{\circ}$ to $60^{\circ} \mathrm{N}$, associated with the subtropical and the polar jets. Essential features include the enhanced wind velocities near Japan and the east coast of the United States and a strong poleward component over the far North Atlantic. At low latitudes the jet stream level winds are weak and predominantly easterly, consistent with observations. For purposes of this work, however, the most relevant dynamical quantities are the meridional transport of water vapor, heat, and angular momentum. Comparison of these quantities predicted by our GCM and observations [e.g., Oort and Rasmusson, 1971] indicate agreement generally better than $75 \%$. This provides strong evidence that the GCM can simulate the transport of trace species to a comparable accuracy, which should be adequate for the present investigation. Another relevant question is the accuracy of the coarse resolution model used in this work compared with a finer resolution model. A comparative study [Hansen et al., 1983] performed with a GCM similar but not identical to this one indicates that the

\section{SURFACE WINDS}

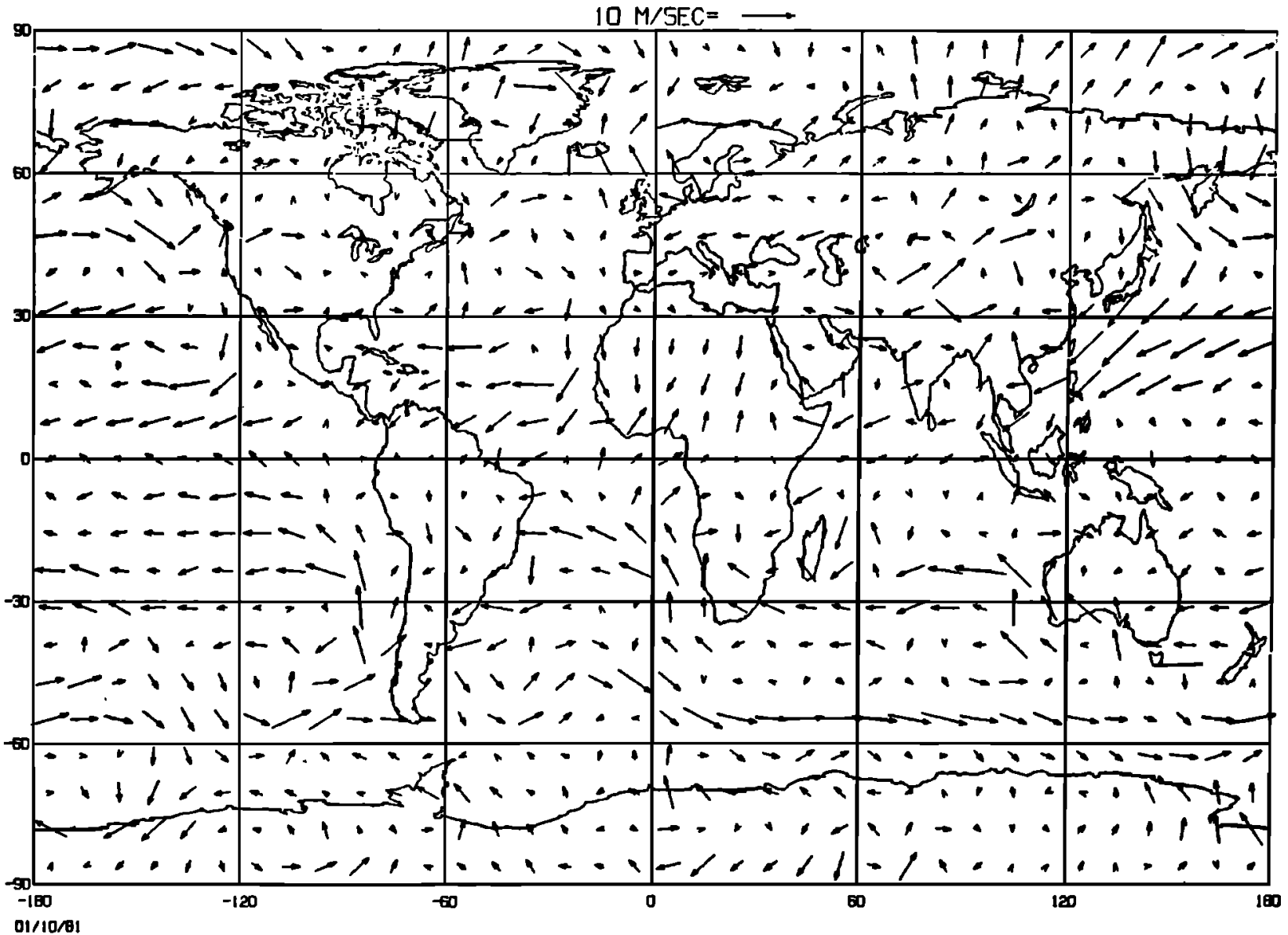

Fig. 1a. Surface winds predicted by the general circulation model used for tracer studies. 
transport properties of the coarse resolution $\left(8^{\circ} \times 10^{\circ}\right)$ model are similar to those of a model with twice the horizontal resolution $\left(4^{\circ} \times 5^{\circ}\right)$.

At hourly time steps the instantaneous mass distribution and the averaged horizontal mass fluxes are fed into the tracer program. These mass fluxes are averaged over 6 hour intervals [Mahlman and Moxim, 1978]. The vertical mass fluxes are derived from the horizontal mass fluxes and the continuity equation. We also included monthly averaged vertical mixing by dry and moist convection. Advection of a tracer is accomplished by a novel finite differencing technique. For each grid box we predict four prognostic quantities: the mean concentration of the tracer $n$ and its spatial gradient $\nabla n$. The scheme determines the four quantities for the next time step by using an upstream method. This algorithm is comparable in accuracy to a fourth-order scheme [Mahlman and Sinclair, 1977], but it has much less numerical noise. The mathematical details are presented by Russell and Lerner [1981].

The chemical sources and sinks of $\mathrm{CO}$ in the tracer continuity equation are provided by a simplified chemical model, which is described in greater detail below. The concentration of the $\mathrm{OH}$ radical at each grid point is calculated by using the current abundance of $\mathrm{CO}$. We then use this value of $\mathrm{OH}$ to calculate the methane oxidation source (R16) as well as the chemical sink (R18) for CO. The values of $\mathrm{OH}$ are updated monthly, which is generally adequate, as indicated by comparisons with test runs in which the updating is done every 10 days.
The nonphotochemical sources and sinks are assumed to be time independent and are modeled as constant release rates or destruction coefficients over the relevant surfaces.

Each experiment starts with a uniform distribution of $\mathrm{CO}$, with a volume mixing ratio $1 \times 10^{-7}$. The tracer model is then run for 4 years, repeatedly by using one year's wind data generated by the general circulation model. That the tracer model has reached steady state in the fourth year is indicated by the lack of change in the global $\mathrm{CO}$ distributions between the third and fourth years. An a posteriori check on the mass balance in the tracer model reveals that it conserves mass to better than $1 \%$ per year, which is adequate for the present investigations.

Photochemical production and loss rates in the troposphere are constructed, using the set of reactions shown in Table $1 a$. The zonally averaged $\mathrm{CO}$ distribution is used to generate photochemical equilibrium solutions for the free radicals $\mathrm{OH}$, $\mathrm{HO}_{2}, \mathrm{H}_{2} \mathrm{O}_{2}, \mathrm{O}\left({ }^{1} \mathrm{D}\right), \mathrm{NO}$, and $\mathrm{NO}_{2}$. Distributions of water vapor mixing ratios and temperatures are taken from the general circulation model. Ozone concentrations and their seasonal variations are taken from the observations of Hering and Borden [1964]. The concentrations of $\mathrm{CH}_{4}$ and $\mathrm{H}_{2}$ are set equal to 1.4 and $0.5 \mathrm{ppm}$, respectively, throughout the troposphere. The distribution of $\mathrm{NO}_{x}\left(\mathrm{NO}+\mathrm{NO}_{2}\right)$ is taken from Crutzen and Fishman [1977], with surface values of $0.1 \mathrm{ppb}$ at $40^{\circ} \mathrm{N}$ and northward and $0.05 \mathrm{ppb}$ southward, along with a scale height of $2 \mathrm{~km}$. Because of a lack of data, no seasonal variations are

JET STREAM WINDS

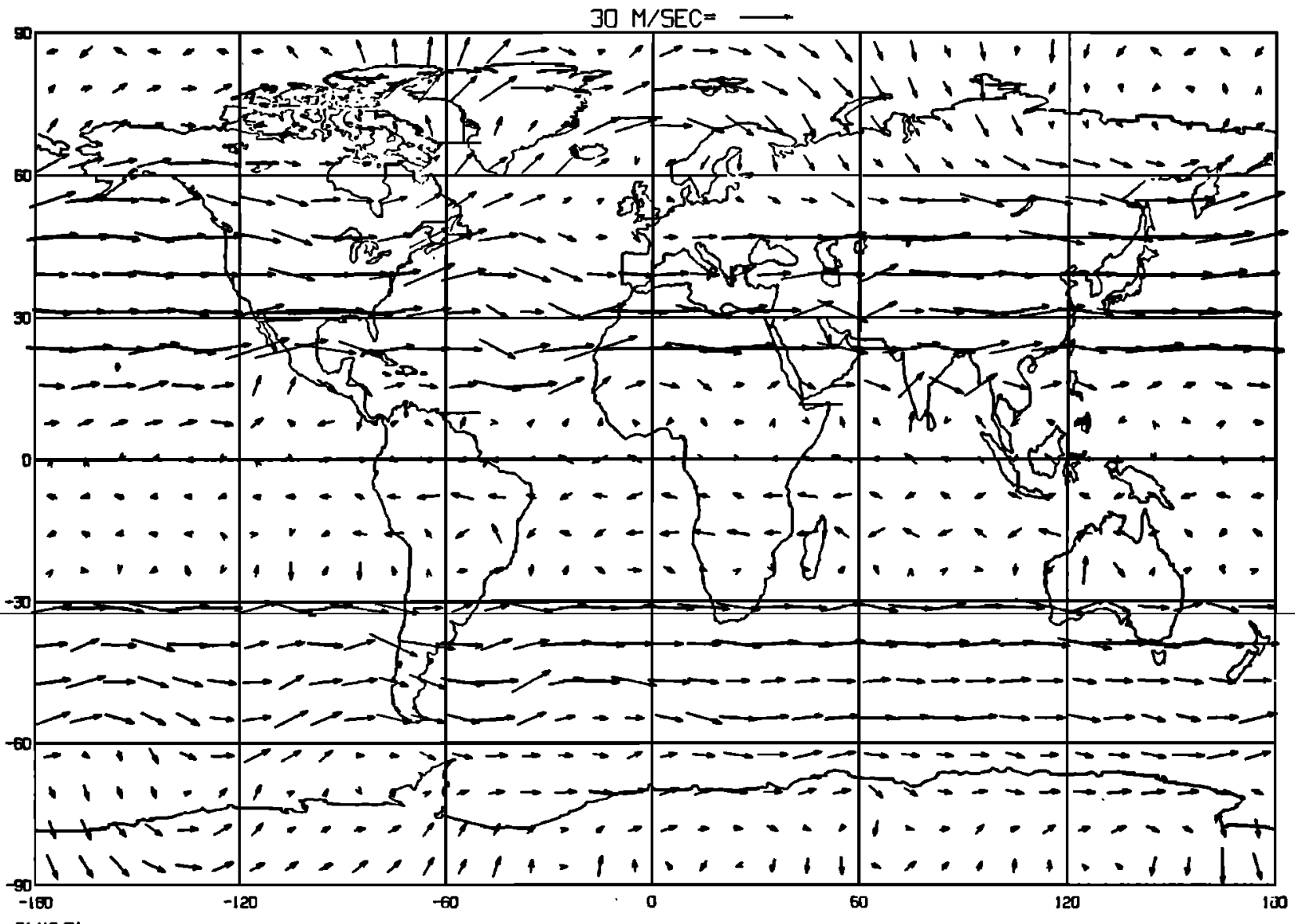

Fig. $1 b$. Jet stream level winds predicted by general circulation model. 
TABLE 1a. Reactions Used for the Calculation of OH Concentration in the Photochemical Model

\begin{tabular}{|c|c|c|c|}
\hline & Reaction & Rate Coefficient & Reference \\
\hline $\begin{array}{l}\text { (R1) } \\
\text { (R2) } \\
\text { (R3) } \\
\text { (R4) } \\
\text { (R5) } \\
\text { (R6) } \\
\text { (R7) } \\
\text { (R8) } \\
\text { (R9) } \\
\text { (R10) } \\
\text { (R11) } \\
\text { (R12) } \\
\text { (R13) } \\
\text { (R14) } \\
\text { (R15) } \\
\text { (R16) } \\
\text { (R17) } \\
\text { (R18) } \\
\text { (R19) } \\
\text { (R20) } \\
\text { (R21) } \\
\text { (R22) }\end{array}$ & 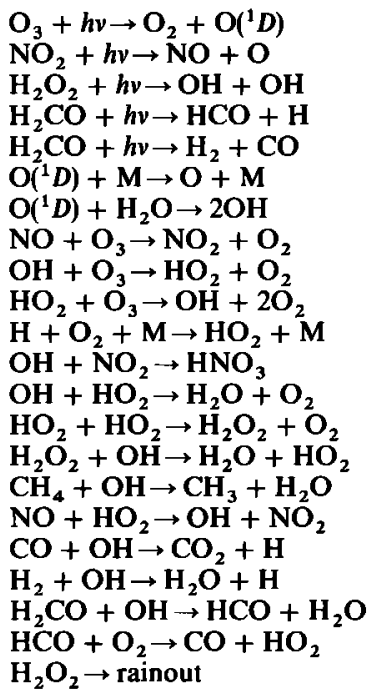 & $\begin{array}{l}J_{1}=1.9 \times 10^{-6} \\
J_{2}=3.6 \times 10^{-3} \\
J_{3}=2.5 \times 10^{-6} \\
J_{4}=5.0 \times 10^{-6} \\
J_{5}=1.3 \times 10^{-5} \\
k_{6}=4.0 \times 10^{-11} \\
k_{7}=2.3 \times 10^{-10} \\
k_{8}=2.1 \times 10^{-12} e^{-1450 / T} \\
k_{9}=1.5 \times 10^{-12} e^{-1000 / T} \\
k_{10}=1.5 \times 10^{-14} e^{-600 / T} \\
k_{11}=1.8 \times 10^{-32} e^{340 / T} \\
k_{12}=1.2 \times 10^{-11} \\
k_{13}=2.0 \times 10^{-10} \\
k_{14}=2.5 \times 10^{-12} \\
k_{15}=1.0 \times 10^{-11} e^{-750 / T} \\
k_{16}=2.3 \times 10^{-12} e^{-1710 / T} \\
k_{17}=4.1 \times 10^{-12} e^{200 / T} \\
k_{18}=1.3 \times 10^{-13}\left(1+p_{\mathrm{alm}}\right) \\
k_{19}=1.8 \times 10^{-11} e^{-2400 / T} \\
k_{20}=1.4 \times 10^{-11} \\
k_{21}=5.7 \times 10^{-12} \\
J_{22}=2.0 \times 10^{-6}\end{array}$ & $\begin{array}{l}\text { (a) } \\
\text { (b) } \\
\text { (b) } \\
\text { (b) } \\
\text { (b) } \\
\text { (b) } \\
\text { (a) } \\
\text { (a) } \\
\text { (b) } \\
\text { (c) } \\
\text { (a) } \\
\text { (d) } \\
\text { (b) } \\
\text { (b) } \\
\text { (b) } \\
\text { (b) } \\
\text { (b) } \\
\text { (b) } \\
\text { (c) } \\
\text { (a) } \\
\text { (e) }\end{array}$ \\
\hline
\end{tabular}

Two- and three-body rate coeflicients are given in units of $\mathrm{cm}^{3} \mathrm{~s}^{-1}$ and $\mathrm{cm}^{6} \mathrm{~s}^{-1}$, respectively. The diurnally averaged mean dissociation rates and rainout rates, (in units $\mathrm{s}^{-1}$ ), are given for spring equinox at $35^{\circ} \mathrm{N}$, at the ground. The value shown for $k_{12}$ is the two-body high pressure limit.

a, NASA, 1977; b, NASA, 1979; c, Logan et al. [1978]; d, Hochanadal [1972] and X. X. DeMore (personal communication, 1978); e, Wofsy [1976].

prescribed for the $\mathrm{NO}_{x}$ concentrations. Recently, Kley et al. [1981] reported somewhat lower $\mathrm{NO}_{x}$ levels in the lower troposphere and higher values in the upper troposphere than we have used. If we had assumed that these values were representative of the background troposphere, our calculated $\mathrm{OH}$ levels in the lower troposphere would have been only marginally affected while upper tropospheric values would have been higher. However, since most of the $\mathrm{CO}$ mass loss occurs in the lowest troposphere and the lifetime of $\mathrm{CO}$ is much longer in the upper troposphere, the impact of this change on our calculated budgets would be very small. The diurnally averaged photodissociation rates are calculated in the usual way, with corrections for Rayleigh scattering [Yung et al., 1980]. The effect of cloud cover is approximated by dividing all dissociation rates in the lower troposphere below the cloud heights $(5 \mathrm{~km})$ by a factor of 2 , since the average cloud cover is about $50 \%$.

In arriving at the simplified chemistry shown in Table $1 a$ we have used several approximations regarding the interactions between the hydroxyl radical, nitrogen oxides, and methane and formaldehyde. Since we fix total $\mathrm{NO}_{x}\left(=\mathrm{NO}+\mathrm{NO}_{2}\right)$, the only $\mathrm{HO}_{x}-\mathrm{NO}_{x}$ couplings are via the ratio,

$$
\frac{\mathrm{NO}}{\mathrm{NO}_{2}}=\frac{J_{2}}{k_{17}\left[\mathrm{HO}_{2}\right]+k_{8}\left[\mathrm{O}_{3}\right]}
$$

and the formation of nitric acid,

$$
\mathrm{NO}_{2}+\mathrm{OH}+\mathrm{M} \rightarrow \mathrm{HNO}_{3}+\mathrm{M}
$$

Since the primary fate of $\mathrm{HNO}_{3}$ formed in (R12) is loss by rainout, it is a good approximation to assume that (R12) is a sink for $\mathrm{HO}_{x}$. The coupling between $\mathrm{HO}_{x}$ and radicals derived from the oxidation of methane is more complicated. We note that to an excellent approximation the destruction of each $\mathrm{CH}_{4}$ molecule leads to the production of one $\mathrm{H}_{2} \mathrm{CO}$ molecule. Hence, the net result of methane chemistry in $\mathrm{HO}_{x}$ can be parameterized by the following expressions,

$$
\begin{gathered}
P(\mathrm{H})=J_{4}\left[\mathrm{H}_{2} \mathrm{CO}\right] \approx \gamma_{2}[\mathrm{OH}] \\
P\left(\mathrm{HO}_{2}\right)=k_{20}\left[\mathrm{H}_{2} \mathrm{CO}\right][\mathrm{OH}]+J_{4}\left[\mathrm{H}_{2} \mathrm{CO}\right] \\
\approx \gamma_{1}[\mathrm{OH}]^{2}+\gamma_{2}[\mathrm{OH}] \\
L(\mathrm{OH})=k_{20}\left[\mathrm{H}_{2} \mathrm{CO}\right][\mathrm{OH}] \approx \gamma_{1}[\mathrm{OH}]^{2}
\end{gathered}
$$

where

$$
\begin{aligned}
& \gamma_{1}=k_{20} k_{16}\left[\mathrm{CH}_{4}\right] /\left(J_{4}+J_{5}+k_{20}[\mathrm{OH}]\right) \\
& \gamma_{2}=J_{4} \gamma_{1} / k_{20}
\end{aligned}
$$

and $P(x)$ and $L(x)$ denote the production and loss rate $\left(\mathrm{cm}^{-3}\right.$ $\left.s^{-1}\right)$ for species $x$, respectively.

\begin{tabular}{|c|c|}
\hline Input to Chemical Model & Output from Chemical Model \\
\hline $\begin{array}{l}T=281^{\circ} \mathrm{K} \\
M=2.3 \times 10^{19} \\
{\left[\mathrm{H}_{2} \mathrm{O}\right]=2.4 \times 10^{17}} \\
{\left[\mathrm{O}_{3}\right]=8.4 \times 10^{11}} \\
{\left[\mathrm{NO}_{x}\right]=1.6 \times 10^{9}} \\
{[\mathrm{CO}]=4.4 \times 10^{12}}\end{array}$ & $\begin{array}{l}{\left[\mathrm{O}^{1} \mathrm{D}\right]=1.7 \times 10^{-3}} \\
{[\mathrm{H}]=1.5 \times 10^{-1}} \\
{[\mathrm{OH}]=5.9 \times 10^{5}} \\
{\left[\mathrm{HO}_{2}\right]=1.8 \times 10^{8}} \\
{\left[\mathrm{H}_{2} \mathrm{O}_{2}\right]=3.5 \times 10^{10}} \\
{\left[\mathrm{NO}^{10}=3.6 \times 10^{8}\right.} \\
{\left[\mathrm{NO}_{2}\right]=1.2 \times 10^{9}}\end{array}$ \\
\hline
\end{tabular}

With these approximations we can calculate the photochemical equilibrium concentrations of the hydroxyl radicals $\left(\mathrm{H}, \mathrm{OH}, \mathrm{HO}_{2}\right.$, and $\mathrm{H}_{2} \mathrm{O}_{2}$ ) by balancing the production and loss rates for these radicals, as given in Table $1 a$ and expressions (2)-(4). This involves solving four simultaneous equations.

TABLE $1 b$. A Representative Calculation of the Major Species in the Simplified Chemical Model for March at $35^{\circ} \mathrm{N}$ at the Ground

The kinetic rate coeficients are taken from Table $1 a$. All number densities are given in units of $\mathrm{cm}^{-3}$. 
However, using the expressions

$$
[\mathrm{H}]=\frac{k_{18}[\mathrm{CO}]+k_{19}\left[\mathrm{H}_{2}\right]+\gamma_{2}}{k_{11}\left[\mathrm{O}_{2}\right] \mathrm{M}}[\mathrm{OH}]
$$

and

$$
\left[\mathrm{H}_{2} \mathrm{O}_{2}\right]=\frac{k_{14}}{J_{3}+k_{15}[\mathrm{OH}]+J_{22}}\left[\mathrm{HO}_{2}\right]^{2}
$$

further simplifies the mathematics to seeking the solution for only two nonlinear algebraic equations in two unknowns $(\mathrm{OH}$ and $\mathrm{HO}_{2}$ ). The solution is then used to improve the estimate of $\mathrm{NO} / \mathrm{NO}_{2}$ by (1). This procedure converges in a few iterations to better than $10^{-4}$. Table $1 b$ gives a representative example of the concentrations of important radical species calculated by this simplified chemical model. The approximate scheme (1) $(6)$ calculates $\mathrm{HO}_{x}$ concentrations that are within $10 \%$ of those computed by using the more extensive set of reactions in our one-dimensional photochemical model [Yung et al., 1980].

The stratospheric photochemical parameters are taken from two-dimensional model calculations by using the reaction scheme of Yung et al. [1980], in which the latitudinal distribution of the long-lived species $\left(\mathrm{Cl}_{x}, \mathrm{NO}_{x}, \mathrm{CH}_{4}\right.$, etc.) are prescribed by projecting the one-dimensional model results along preferred mixing surfaces [McElroy et al., 1976]. The distribution of stratospheric water vapor is taken from Wofsy [1976].

\section{EXPERIMENTS}

For this investigation, we performed a total of eight experiments. They were dessigned to consider a number of hypothetical sources and sinks in order to derive a budget consistent with atmospheric observations. The input parameters for these models are discussed below, and a brief summary appears in Table 2.

In experiment $\mathrm{T} 1$ we included an anthropogenic source of $6.3 \times 10^{14} \mathrm{~g} / \mathrm{yr}$, [Seiler, 1974]. The latitudinal distribution of this source was prescribed by assuming that emissions are proportional to energy consumption in a given latitude belt. The data for energy consumption were taken from Darmstadter et al. [1971]. No seasonal variation in the anthropogenic source was included, as this effect is thought to be small [Hall et al., 1975]. We also included a source from methane oxidation and a sink due to the oxidation of $\mathrm{CO}$ by reaction with $\mathrm{OH}$. Both processes were distributed throughout the troposphere and stratosphere.

Tracer experiment $\mathrm{T} 2$ included the same source and sink terms as $\mathrm{T} 1$ except that the source from methane oxidation and loss by reaction with $\mathrm{OH}$ radicals were both arbitrarily reduced after each calculation to ensure a mean global abundance close to observations. This was done to determine the sensitivity of the model to the $\mathrm{OH}$ value.

Experiment $\mathrm{T} 3$ included, in addition to the sources and sinks used in T1, a plant source of magnitude $4.3 \times 10^{14} \mathrm{~g} / \mathrm{yr}$, equal to the minimum estimate of Zimmerman et al. [1978], while in experiment T4 we used their upper limit of $1.3 \times 10^{15} \mathrm{~g} / \mathrm{yr}$. The latitudinal distribution of these sources was also taken from Zimmerman et al. for both experiments. Although the equatorial ground source has been parameterized by using values estimated by Zimmerman et al. [1978] for NMHC oxidation, there are other possibilities. For example, Crutzen et al. [1979] have suggested that the burning of vegetation either by forest fires or slash and burn agricultural practices, which are concentrated mainly in the tropics, might be a large CO source.

In experiment $\mathrm{T} 5$, we used the anthropogenic source and included the methane oxidation source and $\mathrm{OH}$ oxidation sink only in the stratosphere, to investigate the importance of transport to the stratosphere as a sink [Newell, 1977] and to isolate the effects of tropospheric photochemistry. Based on previous experience with this combination, we anticipated that an additional loss term would be necessary; thus, in experiment T6 we parameterized a soil sink by using a deposition velocity of $4 \times 10^{-2} \mathrm{~cm} / \mathrm{s}$, as estimated by Liebl and Seiler [1976].

In experiment $\mathrm{T} 7$, we incorporated an ocean source, which might be associated with marine biological activity. While estimates of a potential oceanic source vary widely, we have used

TABLE 2. Summary of Sources and Sinks Used in the Construction of the Tracer Models

\begin{tabular}{ccc}
\hline Experiment & \multicolumn{1}{c}{ Sources } & Sinks \\
\hline $\mathrm{T} 1$ & $\begin{array}{c}\text { anthropogenic (a) } \\
\mathrm{CH}_{4} \text { oxidation (b) } \\
\text { anthropogenic (a) } \\
1 / 2 \mathrm{CH}_{4} \text { oxidation (b) } \\
\text { anthropogenic (a) } \\
\mathrm{CH}_{4} \text { oxidation (b) } \\
\text { plant source MIN (c) } \\
\text { anthropogenic (a) } \\
\mathrm{CH}_{4} \text { oxidation (b) } \\
\text { plant source max (d) }\end{array}$ & $\mathrm{CO}+\mathrm{OH}$ \\
$\mathrm{T} 3$ & $\begin{array}{c}\text { anthropogenic (a) } \\
\mathrm{CH}_{4} \text { oxidation stratosphere (e) } \\
\text { anthropogenic (a) } \\
\mathrm{CH}_{4} \text { oxidation stratosphere (e) } \\
\text { anthropogenic (a) } \\
\mathrm{CH}_{4} \text { oxidation (b) } \\
\text { ocean (g) } \\
\mathrm{CH} \text { oxidation (b) } \\
\text { plant source max (d) }\end{array}$ & $\mathrm{CO}+\mathrm{OH}$ \\
$\mathrm{T} 6$ & $\mathrm{CO}+\mathrm{OH}$ stratosphere (e) \\
$\mathrm{T} 7$ & $\mathrm{CO}+\mathrm{OH}$ stratosphere (e) \\
$\mathrm{T} 8$ & $\mathrm{CO}+\mathrm{OH}$ \\
\hline
\end{tabular}

a, $6.3 \times 10^{14} \mathrm{~g} / \mathrm{yr}^{-1}$ [Seiler, 1974]; b, based on $\mathrm{OH}$ calculated in the chemical model (see text); $\mathrm{c}$, $4.3 \times 10^{14} \mathrm{~g} / \mathrm{yr}^{-1}$ distributed according to Zimmerman et al. [1978], however, we do not distinguish between NMHC and vegetation burning sources; $\mathrm{d}, 1.3 \times 10^{15} \mathrm{~g} / \mathrm{yr}^{-1}$, otherwise same as (c); $\mathrm{e}$, these reactions take place in the stratosphere only, and there is no tropospheric chemistry; $\mathrm{f}$, deposition velocity over soil $=4 \times 10^{-2} \mathrm{~cm} \mathrm{~s}^{-1} ; \mathrm{g}, 4 \times 10^{13} \mathrm{~g} / \mathrm{yr}^{-1}$ [Seiler and Schmidt, 1975]. 


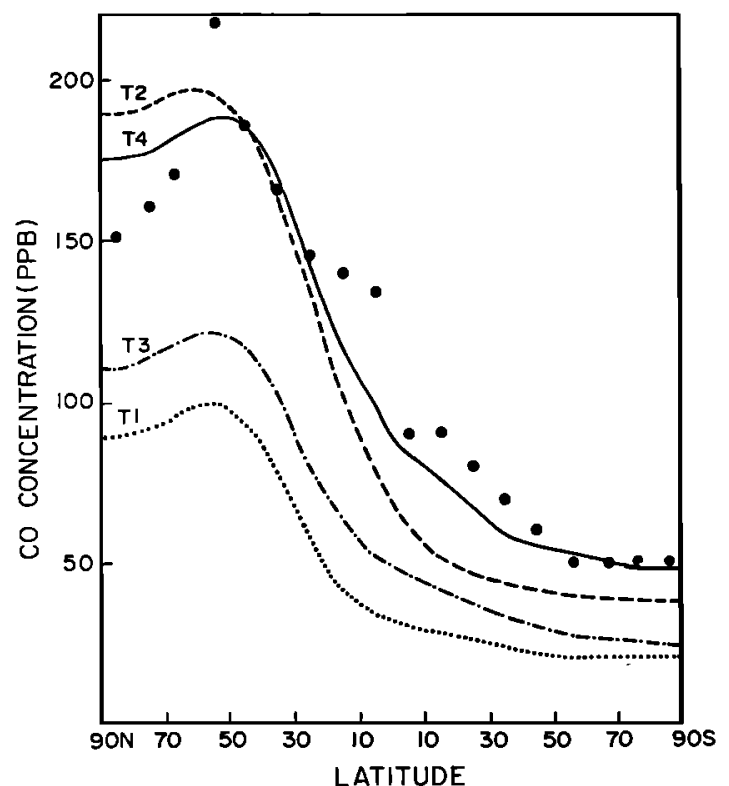

Fig. 2a. Vertically and zonally averaged $\mathrm{CO}$ concentrations as a function of latitude for tracer experiments T1-T4. Observations by Seiler [1974] are shown as full circles.

the (conservative) value of $0.4 \times 10^{14} \mathrm{~g} / \mathrm{yr}$, estimated by Seiler and Schmidt [1975], which was distributed uniformly over the oceans.

Finally, in experiment T8 we included the same sources as in T4, except that the anthropogenic source was excluded in order to investigate the impact of an anthropogenic releases on the global distribution.

The classification of sources into three groupsanthropogenic, $\mathrm{CH}_{4}$ oxidation, and plant-is somewhat arbitrary and is done solely for convenience. For instance, there would be a large anthropogenic component in the plant source, if a major component of that was due to slash and burn agricultural practices.

\section{Results AND Discussion}

Figures $2 a$ and $2 b$ depict the vertically and zonally averaged $\mathrm{CO}$ concentrations, as a function of latitude, calculated in the eight experiments, along with the observed values [after Seiler, 1974]. It is clear from a comparison of the model results with the observations that experiments $\mathrm{T} 2$ and $\mathrm{T} 4$ could produce a meridional distribution similar to that observed. Both models

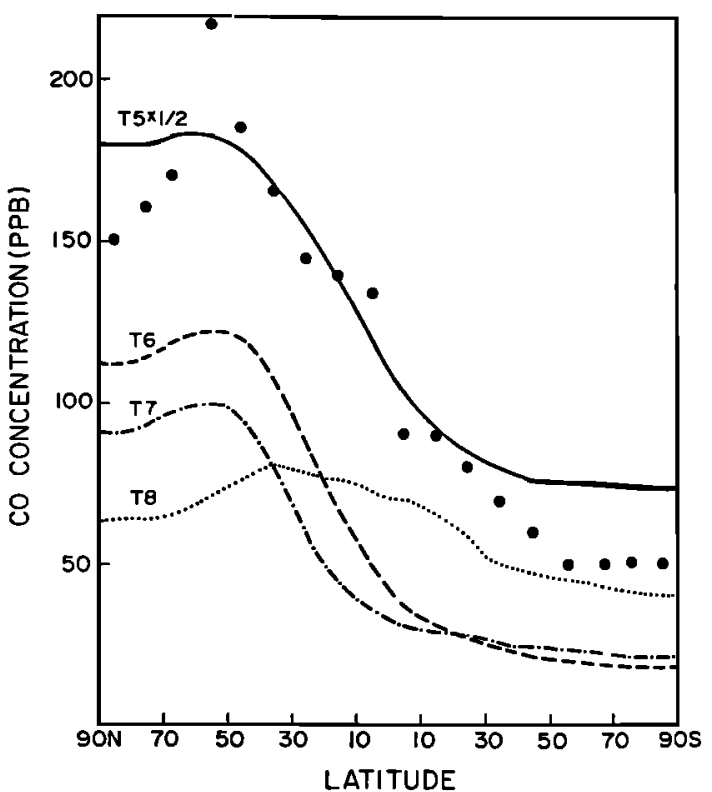

Fig. 2b. Same as Figure $1 a$ for tracer experiments T5-T8. Values shown for experiment T5 have been divided by 2 .

could also satisfy the mean global abundance equally as well. Experiment T5 (which did not consider tropospheric photochemistry at all) produced values roughly twice as large as observed. Unless transport to the stratosphere is substantially underestimated in the model, this result indicates that the stratosphere is not an important sink in the global $\mathrm{CO}$ cycle. When the soil sink was added, as in T6, concentrations were reduced to values lower than observed. Obviously, it would be possible to 'tune' the deposition velocity by varying it within the uncertainty range of Liebl and Seiler [1975] to force better agreement, and, therefore, definitive conclusions about the strength of a soil sink cannot be drawn from this experiment alone. However, as will be discussed later, measurements of the isotopic content of CO [Stevens et al., 1972] can be used to place constraints on the overall importance of a soil sink for the atmospheric $\mathrm{CO}$ budget. In general though, models (T2, T5, and T6) which calculated $\mathrm{OH}$ values lower than those in T4 produced interhemispheric ratios that differed from the observed by $20 \%$ or more. While the meridional distributions produced in experiments $\mathrm{T} 4$ and $\mathrm{T} 5$ are qualitatively similar, they have different causes. In $\mathrm{T} 4$, the $\mathrm{CO}$ abundance in the

TABLE 3. Summary of Results Obtained From the Eight Tracer Experiments

\begin{tabular}{|c|c|c|c|c|c|c|c|c|c|}
\hline Experiments & T1 & $\mathbf{T} 2$ & T3 & $\mathrm{T} 4$ & T5 & T6 & $\mathrm{T} 7$ & T8 & Observations \\
\hline $\mathrm{CO}(\mathrm{ppb})$ & 46 & 95 & 62 & 107 & 241 & 59 & 48 & 65 & 110 \\
\hline$L\left(\mathrm{OH}+\mathrm{CO}, 10^{14} \mathrm{~g} / \mathrm{yr}\right)$ & 15 & 8.9 & 18.6 & 25.9 & 5.7 & 1.8 & 15.3 & 20.6 & \\
\hline$P\left(\mathrm{CH}_{4}\right.$ oxidation $)$ & 8.7 & 2.6 & 7.9 & 6.3 & 0.3 & 0.3 & 8.6 & 7.4 & \\
\hline$P($ Ind $)$ & 6.3 & 6.3 & 6.3 & 6.3 & 6.3 & 6.3 & 6.3 & 6.3 & \\
\hline$P(\mathrm{NMHC})$ & - & - & 4.3 & 13.1 & - & - & - & 13.1 & \\
\hline$L$ (Soil) & - & - & - & - & - & 4.8 & - & - & \\
\hline$P($ Ocean $)$ & - & - & - & - & - & - & 0.4 & - & \\
\hline $\mathrm{OH}\left(\mathrm{cm}^{-3} \times 10^{-5}\right)$ & 10.0 & 3.0 & 9.0 & 7.1 & - & - & 9.9 & 8.4 & \\
\hline $\mathrm{CO}(\mathrm{NH}) / \mathrm{CO}(\mathrm{SH})$ & 2.6 & 3.0 & 2.5 & 2.3 & 1.8 & 3.4 & 2.5 & 1.3 & 2.5 \\
\hline $\mathrm{OH}(\mathrm{NH}) / \mathrm{OH}(\mathrm{SH})$ & 0.7 & 0.7 & 0.7 & 0.7 & - & - & 0.7 & 0.8 & \\
\hline
\end{tabular}

$\mathrm{CO}$ concentrations are given in parts per billion by volume. Units for production and destruction mechanisms are $10^{14} \mathrm{~g} \mathrm{CO} / \mathrm{yr}$. The abbreviation 'Ind' refers to industrial and NMHC to nonmethane hydrocarbon. 
southern hemisphere is governed mainly by local sources and sinks (cf. Figure 5a). In T5, CO-rich air from northern midlatitudes is entrained into the rising branch of the Hadley circulation and is transported into the stratosphere, where it is destroyed. Stratospheric air that is poor in $\mathrm{CO}$ then enters the mid-latitude southern hemisphere. In both cases, $\mathrm{CO}$-rich air is transported southward and upward by the northern hemispheric branch of the Hadley circulation and CO-poor air is transported northward and upward by the southern hemispheric branch, resulting in a sharp interhemispheric gradient at low altitudes. Since T8 does not include an anthropogenic source, it produces a much smaller interhemispheric gradient.
The latitudinal asymmetry in this model reflects the greater portion of land areas in the northern hemispheric tropics relative to the southern hemisphere. The important assumptions and results of experiments T1-T8 are summarized in Table 3.

The computed seasonal variations of $\mathrm{CO}$ at $55^{\circ} \mathrm{N}$ is shown in Figures $3 a$ and $3 b$ along with observations at Zvenigorod, USSR [Dianov-Klokov et al., 1978]. Figures $3 c$ and $3 d$ show the model-derived seasonal variations at $20^{\circ} \mathrm{N}$. The data are based on the observations of Seiler et al. [1976] at Mauna Loa. Both data sets were shown to be relatively free of local pollution influences, and should be representative of conditions in the clean troposphere. In general, all the models that had produced

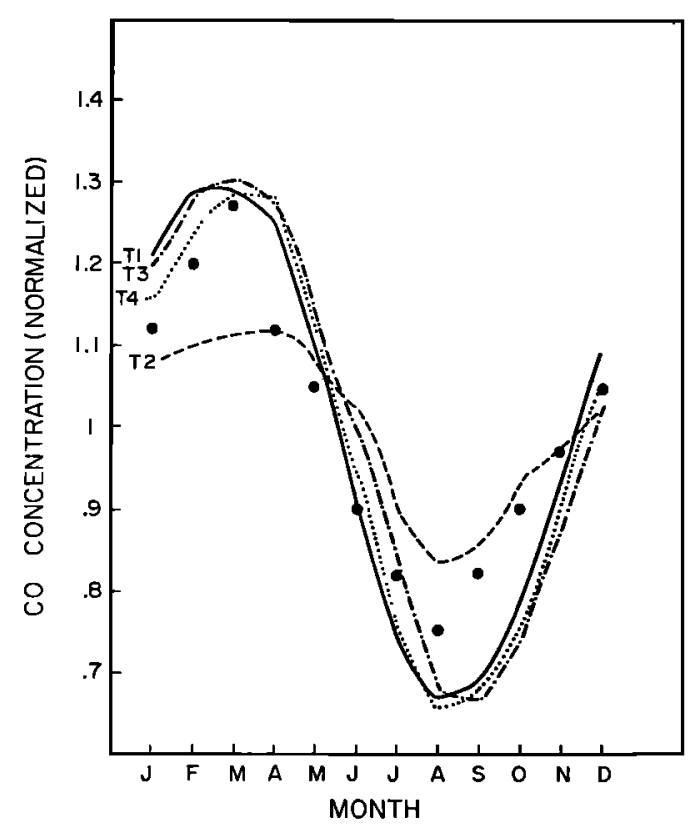

Fig. $3 a$

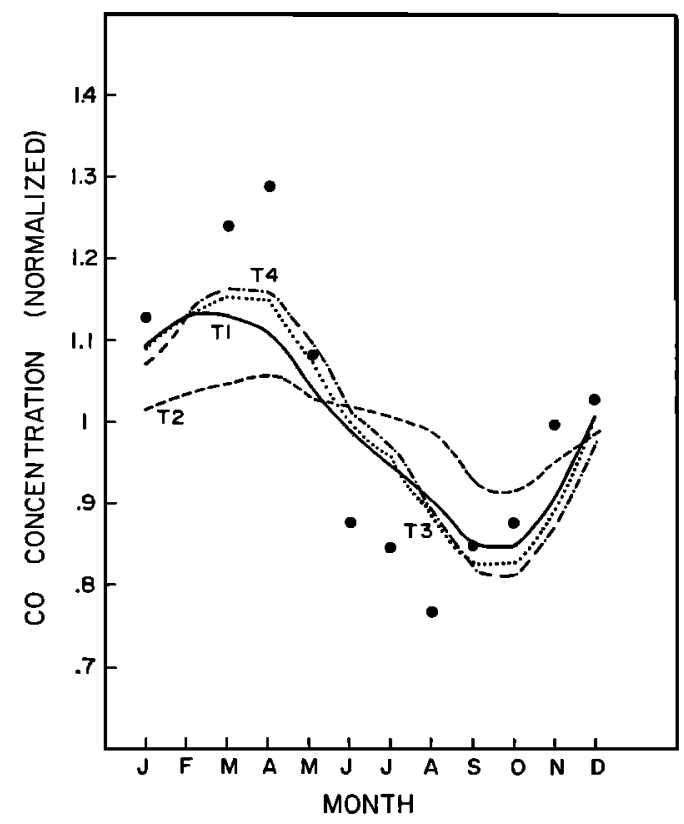

Fig. $3 c$

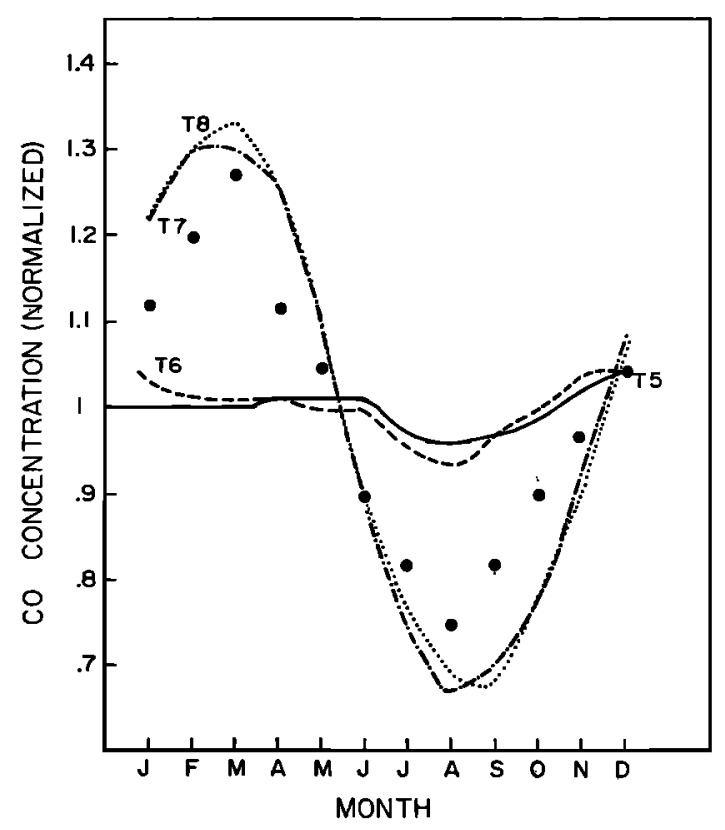

Fig. $3 b$

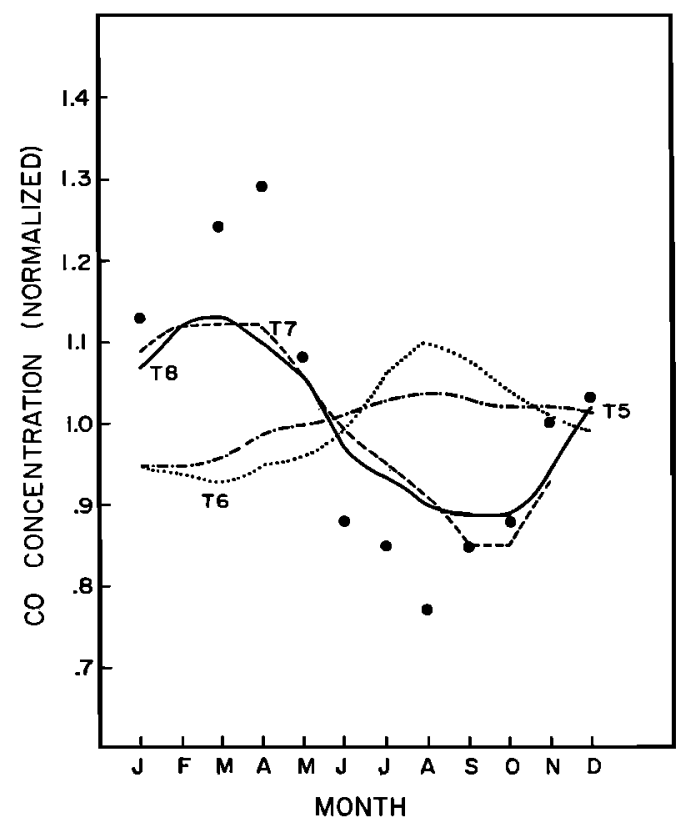

Fig. 3d

Fig. 3. Calculated seasonal variations of CO for tracer experiments (a) $\mathrm{T} 1-\mathrm{T} 4$, at $55^{\circ} \mathrm{N}$; $(b) \mathrm{T} 5-\mathrm{T} 8$ at $55^{\circ} \mathrm{N}$ observed values by Dianov-Klokov et al. [1978]; (c) T1-T4 at $20^{\circ} \mathrm{N}$; (d) T5-T8 at $20^{\circ} \mathrm{N}$ observed values by Seiler et al. [1976]. 


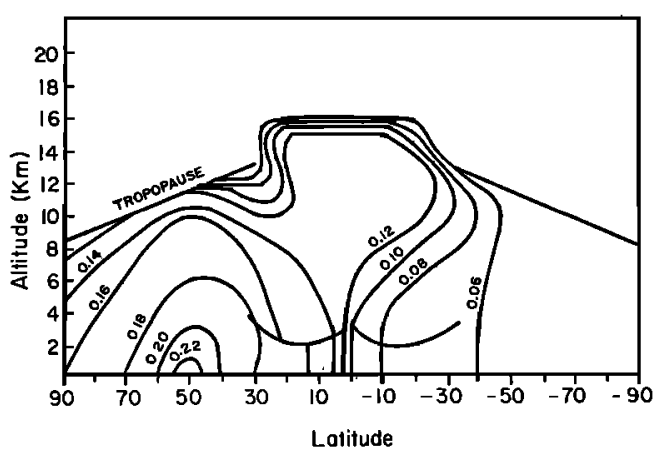

Fig. 4a. Observed latitude-height contours of $\mathrm{CO}$ over the Atlantic Ocean [Seiler and Schmidt, 1974].

OH levels in the troposphere much lower than those calculated in experiment T4 could not satisfactorily reproduce the observed amplitude and phase of the seasonal variation at $50^{\circ} \mathrm{N}$.

The observations of $\mathrm{CO}$ at $55^{\circ} \mathrm{N}$ and $20^{\circ} \mathrm{N}$ show little or no phase difference. This behavior is in striking contrast to the seasonal variations of $\mathrm{CO}_{2}$, which show significant differences between latitude belts [Junge and Czeplak, 1968]. The seasonal variations of $\mathrm{CO}_{2}$ are driven mainly at high latitudes; at high northern latitudes the minimum occurs in late summer, which is 6 months different from the southern hemispheric summer minimum. At low northern latitudes, with the intrusion of air from the southern hemisphere, the phase is delayed. However, the observed seasonal variations of $\mathrm{CO}$ appear to be driven uniformly with latitude, indicating a shorter lifetime and a dominance of local sources and sinks. This is consistent with seasonal variations in the $\mathrm{OH}$ concentration as the primary mechanism responsible for the seasonal variations of $\mathrm{CO}$. The concentration of $\mathrm{OH}$ depends strongly on the duration and intensity of UV sunlight. Model-derived $\mathrm{OH}$ values showed little or no variation in the times when maximum or minimum concentrations occur at different latitudes. The seasonal variations of CO observed by Seiler et al. [1976] and DianovKlokov et al. [1978] likewise showed no difference in phase, a difference which would have been expected if the seasonal forcing were to arise from some feature such as a seasonal variation in the anthropogenic input. There is, however, about a $30 \%$ discrepancy in the amplitude observed by Seiler and the results of model T4.

If the seasonal $\mathrm{CO}$ data are accurate, this suggests that local chemistry may be more important and the atmospheric $\mathrm{OH}$

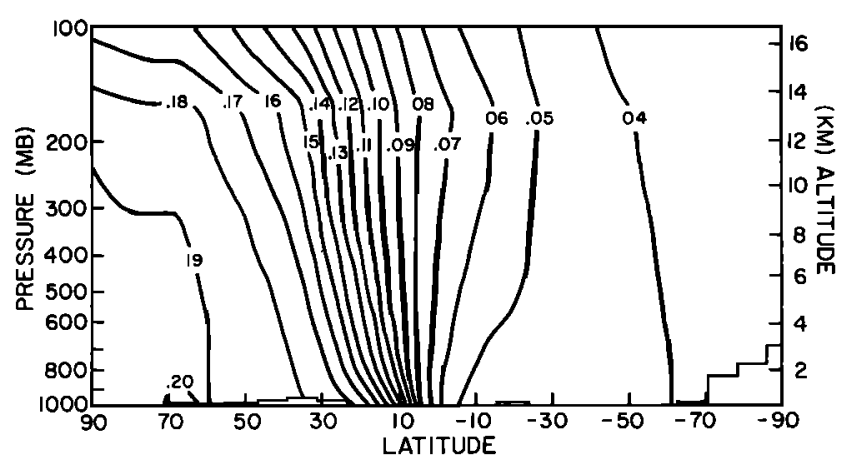

Fig. 4b. Latitude-height contours over the Atlantic Ocean produced by experiment $\mathrm{T} 2$. Values shown are averaged over the last year of the model run. The heights of the pressure levels refer to the global and annual averages. may be even higher than it is in the model. We have examined the sensitivity of the results in a model in which the $\mathrm{OH}$ concentrations were increased by one third over the values in T4. The results showed that both the amplitudes and the phases of the seasonal variations were in much better agreement with observations. Alternatively, there may be a seasonal variation in the strength of the low latitude source. As there is little seasonality in primary productivity in tropics, which is dominated by rain forests, we would expect no seasonal variation in the strength of the tropical source, if the scaling of hydrocarbon emissions to productivity used by Zimmerman et al. [1978] is adopted. There may be a seasonal variation in the CO source derived from vegetation burning. In the northern hemispheric tropics, the dry season is in winter [Richards, 1979]. Enhanced forest fires in this season would contribute a source that could improve the comparison between the model and observations.

T5 and T6, which do not include tropospheric chemistry, show little seasonal variability, while the seasonal variations produced in T2 are somewhat smaller than observed. The comparisons in Figures 2-3 imply that both tropospheric chemistry and the anthropogenic source are necessary components of the $\mathrm{CO}$ budget.

We also investigated the latitude-height distribution of $\mathrm{CO}$. Figure 4 shows an estimate of the observed distribution [Seiler, 1974]. The low level maximum at upper mid-latitudes, presumably due to the anthropogenic source, is apparent, as is a lower latitude upper tropospheric bulge in the CO isopleths. At $10^{\circ} \mathrm{S}$, values increase by more than $75 \%$ between the surface and 12 $\mathrm{km}$. All the model experiments fail to produce this feature except for $\mathrm{T} 3$ and $\mathrm{T} 4$, the experiments that include the plant CO course. Figure $4 b$ shows the result from year 4 for T2. The omission of a low latitude source is primarily responsible for the absence of the equatorial bulge in this model. Figure $4 c$ presents the results for T4. The upper tropospheric bulge is apparent as well as the maximum at high latitudes. The distribution above the tropopause is unrealistic due to the failure of a seven-layer model to adequately resolve the tropopause and thus to model accurately troposphere-stratosphere exchange.

It is of interest to understand how the upper troposphere bulge is produced in T4. As was indicated in the above discussion, T4 concentrations are largely produced locally, and this is true for the vertical distribution as well. The biologically produced $\mathrm{CO}$ at low latitudes is transported vertically, mainly by the model's small-scale convection, in agreement with the mechanism proposed by Falconer and Pratt [1980]. Indication that a local ground source is responsible for the observed bulge comes from the high altitude measurements by Gauntner et al. [1979] of CO and Aitken nuclei over the tropics. Their results

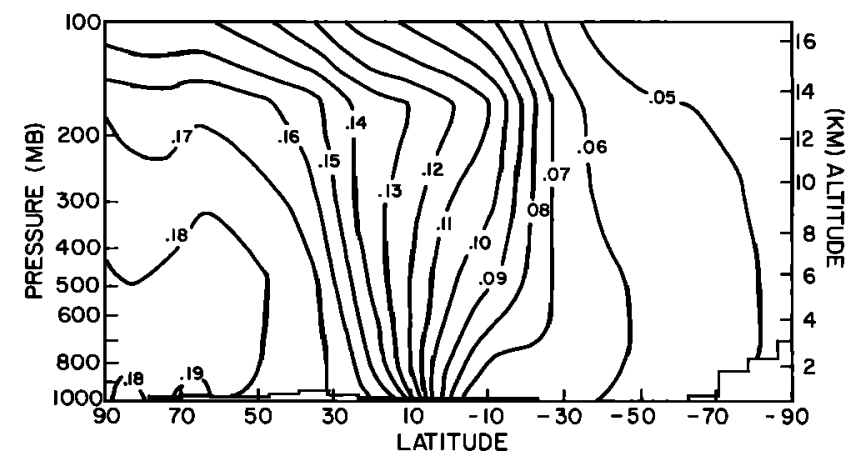

Fig. $4 c$. Same as Figure $3 b$ except for experiment T4. 
show that high $\mathrm{CO}$ concentrations are associated with high Aitken nuclei counts, indicating a common source for both of these quantities. The upper troposphere data of Seiler [1974] were taken over the Atlantic and are similar to those observed by Gauntner et al. [1979] over Africa. In addition, the data of Gauntner et al. show higher values at equatorial latitudes over Africa than over the Pacific. The results of T4 are consistent with these observations. The longer distance from the major northern hemispheric source regions result in lower values over the equatorial Pacific. In T2, the longer lifetime of $\mathrm{CO}$ allows for its more complete redistribution around the globe. The Gauntner et al. data were obtained on only one flight, so more data are needed to check if these are persistent features of the $\mathrm{CO}$ distribution, and to examine the seasonal variability of the interhemispheric transport of $\mathrm{CO}$.

Based on the complete set of experiments, we conclude that $\mathrm{T} 4$ is the most successful combination of sources and sinks tried for simulating the observed CO distribution. It is of interest to understand why the results of experiments $\mathrm{T} 2$ and $\mathrm{T} 4$ could both be reasonably successful in satisfying constraints imposed by (1) the observed global mean abundance and (2) the observed latitudinal distribution, since their chemical lifetimes differ by almost a factor of 3 . The continuity equation may be written as

$$
\frac{\delta M}{\delta t}=H+V+P-L+S
$$

where $M$ is the mass of tracer, $H$ the horizontal convergence associated with transport by eddies and the mean circulation, $P$ and $L$ the chemical production and loss terms, $V$ the vertical transport into the troposphere from the stratosphere, and $S$ the ground source. The results are shown in Figures $5 a$ and $5 b$ for $\mathrm{T} 4$ and $\mathrm{T} 2$, to emphasize the roles of the various terms in different experiments. In experiment $\mathrm{T} 4$, much of the $\mathrm{CO}$ is governed by a local cycle of sources and sinks, with concentrations peaking where the sources are a maximum and in the intervening $30^{\circ}$ latitude belt, where the horizontal convergence from the neighboring zones is significant. In $\mathrm{T} 2$, the distribution at lower latitudes is more strongly influenced by the horizontal convergence. In this case, the long lifetime of $\mathrm{CO}$ allows for its long range advection, but in so doing it also reduces much of its variability.

The results of these experiments imply that the globally averaged $\mathrm{OH}$ concentration is approximately $7 \times 10^{5} \mathrm{~cm}^{-3}$ and cannot be greatly less than this value. Singh [1977] has used observations of the interhemispheric difference of methyl chloroform $\left(\mathrm{CH}_{3} \mathrm{CCl}_{3}\right)$ to deduce globally averaged $\mathrm{OH}$ concentrations of at most $4 \times 10^{5} \mathrm{~cm}^{-3}$. It is of interest to note that the globally averaged $\mathrm{OH}$ concentration calculated in experiment $\mathrm{T} 2$ is approximately the same as derived by Singh in his analysis. However, two recent studies [Jeong and Kaufman, 1979; Kurylo et al., 1979], using independent techniques, have derived a revised rate coefficient for the reaction $\mathrm{CH}_{3} \mathrm{CCl}_{3}$ $+\mathrm{OH}$. This value is about a factor of 2 lower than that used by Singh in his analysis. These new results imply that his derived $\mathrm{OH}$ concentrations should be increased by a factor of 2 and are consistent with values obtained in experiment T4. Isopleths of the mean concentrations of $\mathrm{OH}$ in units of $10^{5}$ molecules $\mathrm{cm}^{-3}$ for the month of January and July computed in experiment T4 are shown in Figures $6 a$ and $6 b$. These results for $\mathrm{OH}$ are in good agreement with those derived recently by Volz et al. [1981] on the basis of ${ }^{14} \mathrm{CO}$ studies.

Experiment T8 is designed to reconstruct the state of the

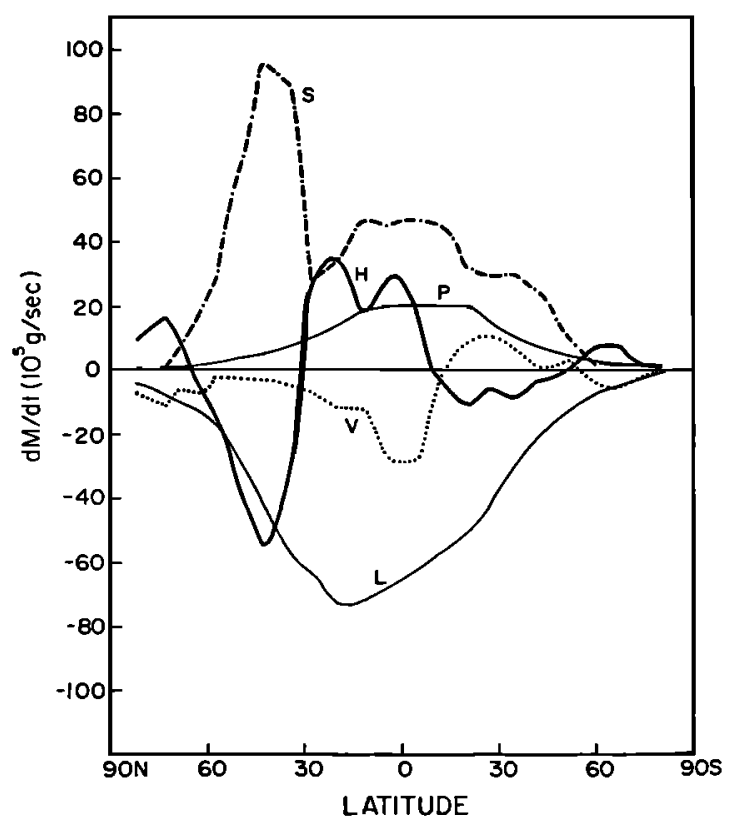

Fig. $5 a$

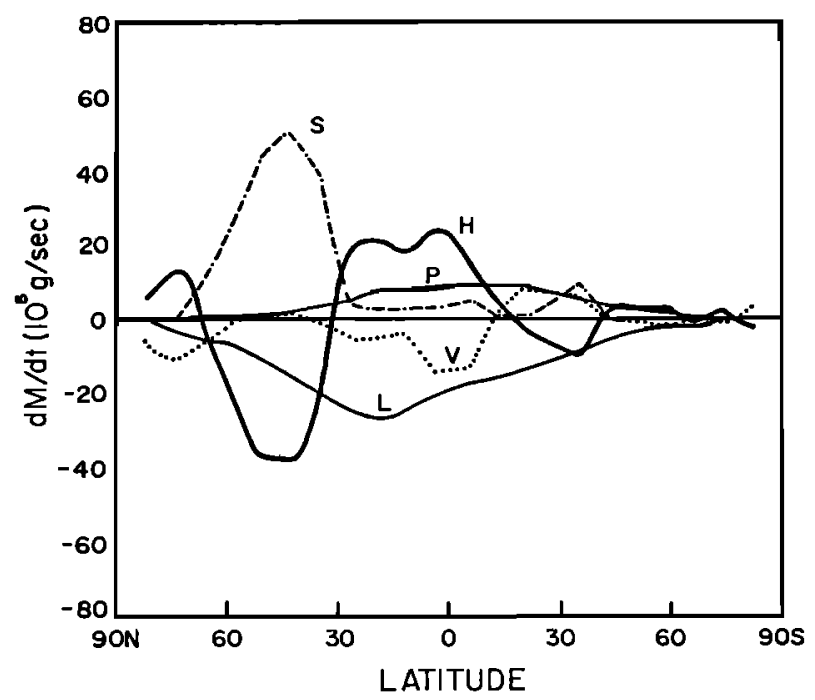

Fig. $5 b$

Fig. 5. Annual $\mathrm{CO}$ budget as a function of latitude. (a) Experiment T4. (b) Experiment $T 2$. $M$ is the mass of tracer; $H$, horizontal flux convergence; $V$, vertical transport into the troposphere from the stratosphere; $\mathbf{P}$ and $\mathrm{L}$, photochemical production and loss terms and $\mathrm{S}$ the nonchemical surface source terms. Units are $10^{5} \mathrm{~g} / \mathrm{s}$.

atmosphere prior to the industrial era. The input parameters for T8 are the same as those for T4 except for the industrial source, which is absent in T8. A comparison between T4 and T8 suggests that there may be a $65 \%$ change in the northern hemispheric $\mathrm{CO}$ concentration due to industrial pollution and a much smaller change in the southern hemisphere. Indeed, a comparison between Shaw's [1958] data taken in Ohio during 1952-1953 and Dianov-Klokov's data in the 1970's in the USSR indicates that there might have been a substantial increase in the $\mathrm{CO}$ concentration during this period. The mean value of $\mathrm{OH}$ in $\mathrm{T} 8$ is about $20 \%$ higher than that in $\mathrm{T} 4$, which suggests that there has been an increase in the tropospheric lifetimes of species such as $\mathrm{CH}_{4}, \mathrm{CH}_{3} \mathrm{Cl}, \mathrm{CH}_{3} \mathrm{Br}$, and $\mathrm{CHCl}_{3}$. In our current investigation we have fixed the source strength of 


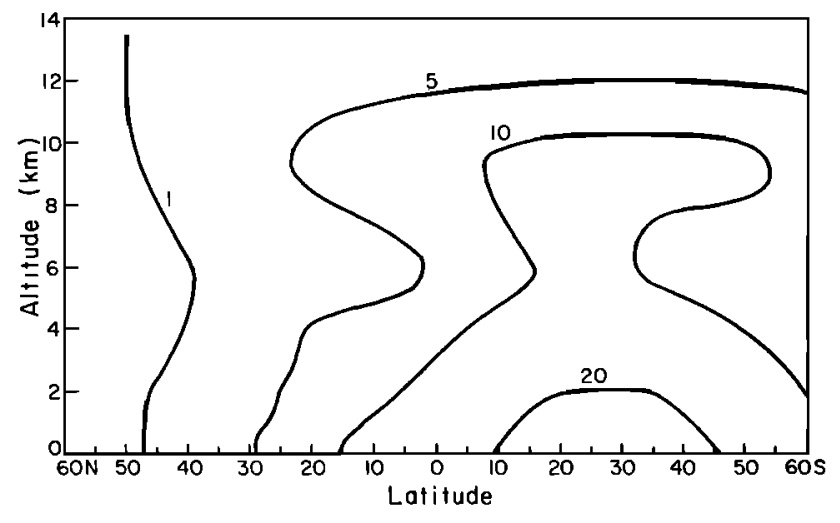

Fig. $6 a$

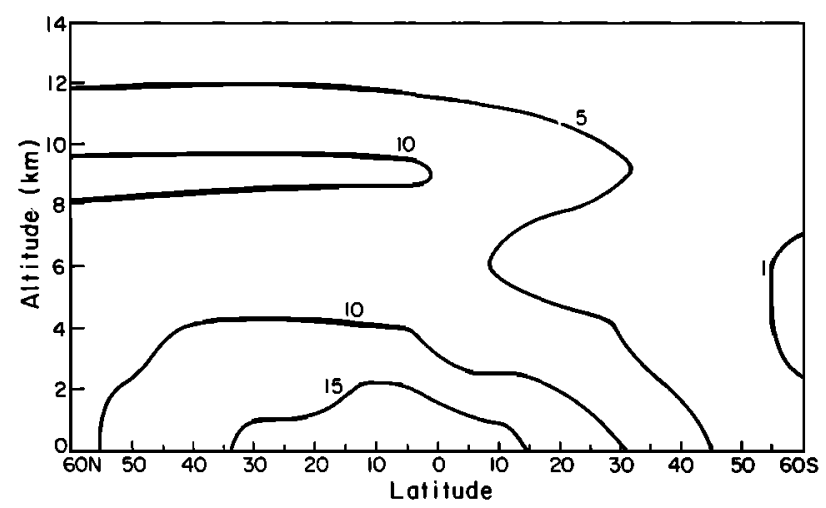

Fig. $6 b$

Fig. 6. Isopleths of the mean (diurnally averaged) $\mathrm{OH}$ concentrations in units of $10^{5}$ molecules $\mathrm{cm}^{-3}$ in experiment T4. (a) January and (b) July.

$\mathrm{CH}_{4}$, the shorter lifetime would have implied an increase of $\mathrm{CH}_{4}$ concentration in the atmosphere. Indeed, the recent observations by Rasmussen et al. [1981] provide strong evidence for an increase of atmospheric $\mathrm{CH}_{4}$.

A primary objective of this paper is to derive $\mathrm{OH}$ concentrations from the behavior of $\mathrm{CO}$ in the model atmosphere. This study is, therefore, more like a diagnostic study of $\mathrm{CO}$ and $\mathrm{OH}$ than a prognostic one. It should be pointed out that the GCM simulation of the CO distribution and its variations provides the best check for the $\mathrm{OH}$ concentrations computed by our chemical model. Owing to the intrinsic difficulty of defining the key inputs such as $\mathrm{O}_{3}, \mathrm{H}_{2} \mathrm{O}, \mathrm{NO}_{x}$, cloud cover, and heterogeneous processes, all of which exhibit great spatial and temporal variability, no chemical model of the troposphere can claim to compute, $\mathrm{OH}$ concentrations from first principles, to better than a factor of 2 . Note that the test of the quality of the $\mathrm{OH}$ calculations is based on the behavior of $\mathrm{CO}$ in the model and is largely independent of the uncertainties in our chemical model.

Global measurements of the ${ }^{18} \mathrm{O} /{ }^{16} \mathrm{O}$ ratio by $\mathrm{CO}$ by Stevens et al. [1972] typically show values much lower than would be derived from the incomplete combustion of fossil fuels. Fractionation by destruction mechanisms cannot be invoked to explain the data. Loss by reaction with $\mathrm{OH}$ radicals (R20) would favor the lighter isotope [Weinstock and Chang, 1974]. Stevens et al. [1972] have measured the fractionation in $\mathbf{C O}$ consumption by soil bacteria and found that it favors the lighter isotopes. All of their northern hemispheric measure- ments indicate a predominance of light isotopic species during the summer when soil scavenging would be at its maximum, which is contrary to what would be expected if the soil were acting as a major sink. It would also be difficult to explain the data by assuming equilibrium of $\mathrm{CO}$ with respect to uptake and release by the soil. By analogy with $\mathrm{CO}_{2}$, release from the soil and from plants may involve no fractionation or again favor the lighter isotope [Keeling, 1973].

The models that do not include vegetation sources have difliculty in explaining the isotopic pattern found in the northern hemisphere, as they predict northern hemispheric $\mathrm{CO}$ to be mainly anthropogenic throughout the year. Experiment T6, which assumes the only sink to be soil scavenging, is also inconsistent with the Stevens et al. [1972] results as the CO in the northern hemisphere would be even heavier than that released from combustion. As was mentioned previously, the seasonal pattern of the ${ }^{18} \mathrm{O} /{ }^{16} \mathrm{O}$ ratio would be exactly opposite to what is observed. These results are consistent with the view that the soil plays a relatively minor role in the $\mathrm{CO}$ cycle.

Since carbon 13 values from fossil fuel $\mathrm{CO}$ overlap those from natural sources, these measurements may not be particularly useful as a diagnostic of source types. Measurements of carbon 14, on the other hand, might be more useful. The use of carbon 14 and oxygen 18 data would then minimize the uncertainties due to mixing of air masses. Figure 7 shows the annually averaged concentrations contributed by each of the sources we have included in experiment T4. They were derived by using each source separately with the $\mathrm{OH}$ field derived by $\mathrm{T} 4$ to determine the loss rate. The figure shows that virtually none of the anthropogenic $\mathrm{CO}$ emitted in the northern hemisphere reaches the southern hemisphere. The results also show that a sizeable fraction of the $\mathrm{CO}$ at middle to high northern latitudes is not anthropogenic. Our results are in qualitative agreement with the major conclusions reached by Weinstock and Niki [1972] and Stevens et al. [1972]. More definitive statements cannot be made until more clean air measurements are available. The two sets of measurements reported above were subject to local anthropogenic influences.

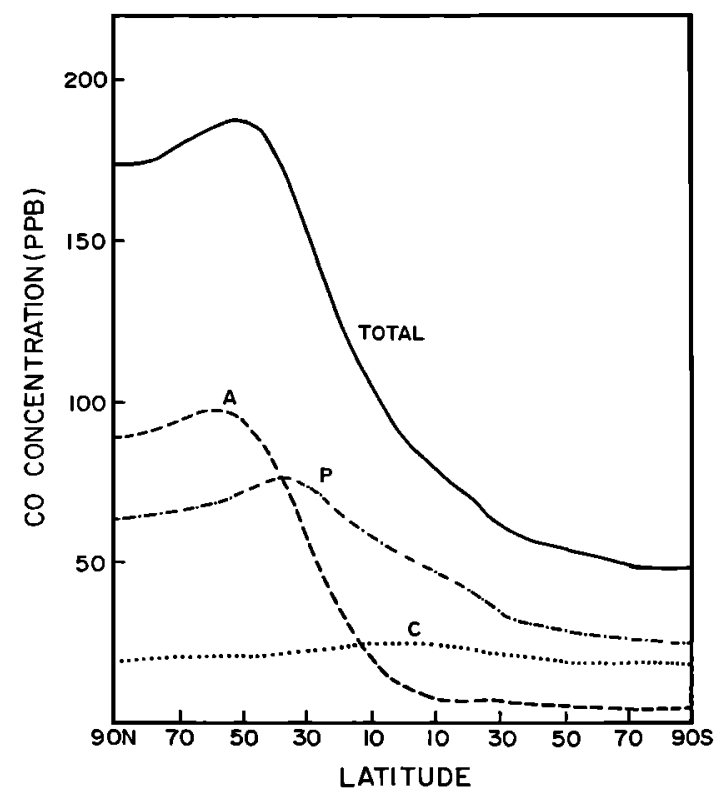

Fig. 7. Contributions of the three source types in experiment T4. The curve labeled $A$ refers to the anthropogenic component, $P$ to the plant source, and $\mathrm{C}$ to the source from methane oxidation. 


\section{CONCLUSIONS}

In this paper, we have performed and studied an extensive set of experiments in search for an understanding of four major features of atmospheric CO: (1) the meridional distribution, (2) the seasonal variation, (3) the equatorial bulge, and (4) the isotopic composition. The results demonstrate the power and versatility of the general circulation model approach, as compared with more traditional analyses [Wofsy, 1976; Crutzen and Fishman, 1977; Hameed and Stewart, 1979]. The most successful experiment, in reproducing all of the above observed features, $\mathrm{T} 4$, requires a large surface source of order $1.3 \times 10^{15}$ $\mathrm{g} / \mathrm{yr}^{-1}$, in addition to anthropogenic and $\mathrm{CH}_{4}$ oxidation sources. This additional source must exist at low latitudes in the Hadley cell regime, in order to produce the observed equatorial bulge.

Our model is consistent with a globally averaged $\mathrm{OH}$ concentration of about $7 \times 10^{5} \mathrm{~cm}^{-3}$. At this $\mathrm{OH}$ level, we are able to simulate the main features of the seasonal variation, observed by Dianov-Klokov et al. [1978] in Zvenigorod $\left(55^{\circ} \mathrm{N}\right)$. The seasonal data obtained by Seiler et al. [1976] at Mauna Loa $\left(20^{\circ} \mathrm{N}\right)$ could be simulated by an even higher concentration of $\mathrm{OH}$ at lower latitudes than that in our T4 experiment or, alternatively, a possible seasonality in the plant source. However, based on our current understanding of the $\mathrm{CH}_{3} \mathbf{C C l}_{3}$ distribution [Singh, 1977; Chang and Penner, 1978; Jeong and Kaufman, 1979; Kurylo et al., 1979], the global mean $\mathrm{OH}$ concentration cannot significantly exceed that calculated in T4. We also conclude, from our model studies, that the globally averaged $\mathrm{OH}$ concentration cannot be significantly lower than that calculated in experiment T4. The observed variability of $\mathrm{CO}$ is not obtained in models $\mathrm{T} 2, \mathrm{~T} 5$, and T6, implying that a shorter chemical lifetime and hence additional sources are required. The results of the latter models are also inconsistent with observations of the isotopic content of $\mathrm{CO}$. Of course the accuracy of quantitative inferences based on the lifetime of $\mathrm{CO}$ are dependent on the general circulation model's ability to simulate atmospheric transport. To provide an independent assessment of tropospheric $\mathrm{OH}$, we are planning to study $\mathrm{CH}_{3} \mathrm{CCl}_{3}$ including tests with improved vertical resolution for the general circulation model.

No doubt a different and perhaps more elaborate combination of sources and sinks and $\mathrm{OH}$ concentrations could also reproduce the observed features of $\mathrm{CO}$. However, we have attempted to construct a model with the fewest number of assumptions possible, and within the current small set of assumptions we are confident of the uniqueness of our results. We expect to improve and refine our models as more $\mathrm{CO}$ measurements become available.

Measurements of the isotopes of $\mathrm{CO}$ formed by various mechanisms such as vegetation burning and the oxidation of hydrocarbons such as isoprenes and terpenes could be valuable in estimating the relative roles of these processes. Measurements of the seasonal variation of total $\mathrm{CO}$ concentration, and the isotopic composition at remote lications could be used with data on the source characteristic s to further quantify the magnitudes of the sources. Locations alieady in use for monitoring $\mathrm{CO}_{2}, \mathrm{~N}_{2} \mathrm{O}$, and chlorofluorocarbons could be used for this purpose.

Acknowledgments. We thank Elaine Matthews for helpful discussions concerning seasonality in tropical vegetation. One of us (J.P.) was supported by an NAS-NRC Resident Research Associateship during the course of this work.

\section{REFERENCES}

Atkinson, G., and J. Sandler, Mean cloudiness and gradient level wind charts over the tropics, Tech. Rep. 215, Air Weather Service, USAF, Scott AFB, Illinois, 1970.

Bates, D. R., and A. E. Witherspoon, The photochemistry of some minor constituents of the earth's atmosphere, Mon. Not. R. Astron. Soc., $112,101-124,1952$.

Biermann, H. W., C. Zetsch, and F. Stuhl, On the pressure dependence of the reaction of $\mathrm{HO}$ and $\mathrm{CO}$, Ber. Bunsenges. Phys. Chem., 82, $633-639,1978$.

Chang, J. S., and J. E. Penner, Analysis of global budgets of halocarbons, Atmos. Environ., 12, 1867-1873, 1978.

Crutzen, P. J., and J. Fishman, Average concentrations of $\mathrm{OH}$ in the troposphere and the budgets of $\mathrm{CH}_{4}, \mathrm{CO}, \mathrm{H}_{2}$, and $\mathrm{CH}_{3} \mathrm{CCl}_{3}, \mathrm{Ge}$ ophys. Res. Lett., 4, 321-324, 1977.

Crutzen, P. J., L. E. Heidt, J. P. Krasnec, W. H. Pollack, and W. Seiler, Biomass burning as a source of atmospheric gases $\mathrm{CO}, \mathrm{H}_{2}, \mathrm{~N}_{2} \mathrm{O}$, $\mathrm{NO}, \mathrm{CH}_{3} \mathrm{Cl}$, and $\mathrm{COS}$, Nature, 282, 253-256, 1979.

Darmstadter, J., P. D. Teitelbaum and J. G. Polach, Energy in the World Economy: A Statistical Review of Trends in Output, Trade, and Consumption Since 1925, Johns Hopkins Press, Baltimore, 1971.

Dianov-Klokov, V. I., Ye. V. Fokeyeva, and L. N. Yurganov, A study of the carbon monoxide content of the atmosphere, Izv. Atm. Ocean Phys., 14, 263-270, 1978.

Falconer, P., and R. Pratt, Comments on 'Experimental guidance for interhemispheric transport for airborne carbon monoxide measurements," J. Appl. Meteorol., 19, 338-339, 1980.

Gauntner, D. J., T. Nyland, M. Tiefermann, and T. Dudzinski, Measurements of carbon monoxide, condensation nuclei, and ozone on a B 747SP, Geophys. Res. Lett., 6, 167-170, 1979.

Hall, C. A. S., C. A. Edkahl, and D. E. Wartenberg, A fifteen-year record of biotic metabolism in the northern hemisphere, Nature, 255, 136-138, 1975.

Hameed, S., and R. W. Stewart, Latitudinal distribution of the sources of carbon monoxide in the troposphere, Geophys. Res. Lett., 6, 841-844, 1979.

Hansen, J. E., G. Russell, D. Rind, P. Stone, A. Lacis, S. Lebedeff, R. Reudy, and L. Travis, Efficient three-dimensional global models for climate studies: Models I and II, Mon. Weather Rev., in press, 1983.

Hering, W. S., and T. R. Borden, Ozonesonde observations over North America, Doc. AFCRL-64-30 $(1,2)$, U.S. Air Force Cambridge Res. Lab., Bedford, Mass., 1964.

Hochanadel, C. J., J. A. Ghormley, and P. J. Ogren, Absorption spectra and reaction kinetics of the $\mathrm{HO}_{2}$ radical in the gas phase, J.Chem. Phys., 56, 4426-4432, 1972.

Jeong, K.-M., and F. Kaufman, Rates of the reactions of 1,1,1Trichloroethane 1,1,2-Trichloroethane with $\mathrm{OH}$, Geophys. Res. Lett., 6, 757-759, 1979.

Junge, C., and G. Czeplak, Some aspects of the seasonal variation of carbon dioxide and ozone, Tellus, 20,422-434, 1968.

Keeling, C. D., The carbon dioxide cycle: Reservoir models to depict the exchange of atmospheric carbon dioxide with the ocean and land plants, in Chemistry of the Lower Atmosphere, edited by S. I. Rasool, Plenum, New York, 1973.

Kley, D., J. W. Drummond, M. McFarland, and S. C. Liu, Tropospheric profiles of NO,$J$. Geophys. Res., 86, 3153-3161, 1981.

Kurylo, M. J., P. C. Anderson, and O. Klais, A flash photolysis resonance fluorescence investigation of the reaction $\mathrm{OH}+\mathrm{CH}_{3} \mathrm{CCl}_{3} \rightarrow$ $\mathrm{H}_{2} \mathrm{O}+\mathrm{CH}_{2} \mathrm{CCl}_{3}$, Geophys. Res. Lett., 6, 760-762, 1979.

Levy, H., II, Normal atmosphere: Large radical and formaldehyde concentrations predicted, Science, 173, 141-143, 1971.

Liebl, K. H., and W. Seiler, $\mathrm{CO}$ and $\mathrm{H}_{2}$ destruction at the soil surface in, Microbial Production and Utilization of Gases, edited by $\mathbf{H}$. G. Schlegel, G. Gottschalk, and N. Pfenning, Publisher, Location, 1976.

Logan, J. A., M. J. Prather, S. C. Wofsy, and M. B. McElroy, Atmospheric chemistry: Response to human influence, Phil. Trans. $R$. Soc., Ser. A, 290, 187-234, 1978.

Logan, J. A., M. J. Prather, S. C. Wolsy, and M. B. McElroy, Tropospheric chemistry: A global perspective, J. Geophys. Res., 86, 7210 7254, 1981.

Mahlman, J. D., and W. J. Moxim, Tracer simulation using a global general circulation model: Results from a mid-latitude instantaneous source experiment, J. Atmos. Sci., 35, 1340-1374, 1978.

Mahlman, J. D., and R. W. Sinclair, Tests of various numerical algorithms applied to a simple trace constituent air transport problem in Fate of Pollutants in the Air and Water Environment, edited by I. $\mathrm{H}$. Suffet, pp. 223-252, John Wiley, New York, 1977. 
McConnell, J. C., M. B. McElroy, and S. C. Wolsy, Natural sources of atmospheric CO, Nature, 233, 187-188, 1971.

McElroy, M. B., J. W. Elkins, S.. C. Wolsy, and Y. L. Yung, Sources and sinks for atmospheric $\mathrm{N}_{2} \mathrm{O}$, Rev. Geophys. Space Phys., 14, 143-150, 1976.

Migeotte, M. V., The fundamental band of carbon monoxide at $4.7 \mu$ in the solar spectrum, Phys. Rev., 75, 1108-1109, 1949.

NASA, Chlorofluoromethanes and the stratosphere, edited by R. D. Hudson, RP-1010, 1977.

NASA, Chemical kinetic and photochemical data for use in stratospheric modeling, Eval. 2, NASA Panel for Data Evaluation, JPL7927, Jet Propul. Lab., Pasadena, Calir., 1979.

Newell, R., One-dimensional models: A critical comment, and their application to carbon monoxide, J. Geophys. Res., 82, 1449-1450, 1977.

Noxon, J. F., Tropospheric $\mathrm{NO}_{2}$, J. Geophys. Res., 83, 3051-3057, 1978.

Noxon, J. F., Correction, J. Geophys. Res., 85, 4560-4561, 1980.

Oort, A. and E. Rasmusson, Atmospheric circulation statistics, NOAA Prof. Pap. 5, 1971.

Rasmussen, R. A., and M. A. K. Khalil, Atmospheric methane $\left(\mathrm{CH}_{4}\right)$ : Trends and seasonal cycles, J. Geophys. Res., 86, 9826-9832, 1981.

Richards, P. W., The Tropical Rain Forest, Cambridge University Press, New York, 1979.

Russell, G. L., and J. A. Lerner, A new finite difference scheme for the tracer transport equation, J. Appl. Meteorol. 29, 1483-1498, 1981.

Seiler, W., The cycle of atmospheric CO, Tellus, 26, 116-135, 1974.

Seiler, W., H. Giehl, and $H$. Ellis, A method for monitoring of background $\mathrm{CO}$ and first results of continuous $\mathrm{CO}$ registrations on Mauna Loa Observatory, Spec. Env. Rep. 10, World Meteorol. Organ., Geneva, Switzerland, 1976.

Seiler, W., and U. Schmidt, New aspects of $\mathrm{CO}$ and $\mathrm{H}_{2}$ cycles in the atmosphere, paper presented at Proceedings International Conference on Structure, Composition, General Circulation of Upper and Lower Atmospheres and Possible Anthropogenic Perturbations, JAMAP, 1974
Shaw, J. H., The abundance of atmospheric carbon monoxide above Columbus, Ohio, Astrophys. J., 128, 428-440,1958.

Singh, H. B., Atmospheric halocarbons: Evidence in favor of reduced average hydroxyl radical concentration in the troposphere, Geophys. Res. Lett., 4, 101-104, 1977.

Stevens, C. M., L. Krout, D. Walling, A. Venters, A. Engelkemeir, and L. E. Ross, Isotopic composition of atmospheric carbon monoxide, Earth Planet. Sci. Lett., 16, 147-165, 1972.

Sze, N. D., Anthropogenic CO emissions: Implications for atmospheric CO-OH-CH 4 cycle, Science, 195, 673-675, 1977.

Volz, A., D. H. Ehhalt, and R. G. Derwent, Seasonal and latitudinal variation of ${ }^{14} \mathrm{CO}$ and the tropospheric concentration of $\mathrm{OH}$ radicals, J. Geophys. Res., 86, 5163-5171, 1981.

Weinstock, B., and T. Y. Chang, The global balance of carbon monoxide, Teltus, 26, 108-115, 1974.

Weinstock, B., and $H$. Niki, Carbon monoxide balance in nature, Science, 176, 290-292, 1972.

Wofsy, S. C., Interactions of $\mathrm{CH}_{4}$ and $\mathrm{CO}$ in the earth's atmosphere, Ann. Rev. Earth Planet. Sci., 4, 441-469, 1976.

Yung, Y. L., M. B. McElroy, and S. C. Wofsy, Atmospheric halocarbons: A discussion with emphasis on chloroform, Geophys. Res. Lett., 2, 397-399, 1975.

Yung, Y. L., J. P. Pinto, R. T. Watson, and S. P. Sander, Atmospheric bromine and ozone perturbations in the lower stratosphere, $J$. Atmos. Sci., 37, 339-353, 1980.

Zimmerman, P. R., R. B. Chatfield, J. Fishman, P. J. Crutzen, and P. L. Hanst, Estimates of the production of $\mathrm{CO}$ and $\mathrm{H}_{2}$ from the oxidation of hydrocarbon emissions from vegetation. Geophys. Res. Lett., $5,679-682,1978$.

(Received October 20, 1980; revised December 31, 1982; accepted January 10, 1983.) 